\title{
Modelling shear strength of compacted soils
}

\author{
Sam Bulolo ${ }^{1}$, and Eng Choon Leong ${ }^{1, *}$ \\ ${ }^{1}$ Nanyang Technological University, School of Civil and Environmental Engineering, Singapore
}

\begin{abstract}
Compacted soils constitute most engineering projects such as earth dams, embankments, pavements, and engineered slopes because of their high shear strength and low compressibility. The shear strength of compacted soils is a key soil parameter in the design of earth structures but it is seldom determined correctly due to their unsaturated state. The shear strength of compacted soils can be better evaluated under the framework of unsaturated soil mechanics. Saturated and unsaturated tests were conducted on compacted specimens using conventional direct shear apparatus under constant water content condition. Tests were conducted at different water contents and net normal stresses. The main objective of this study is to develop a shear strength model for compacted soils. Initial matric suction was measured before the test using the filter paper method. The two-stress state variables together with the extended MohrCoulomb failure criterion for unsaturated soils were used to obtain a lower bound model of the shear strength. The model was demonstrated using published data.
\end{abstract}

\section{Introduction}

Compacted soils constitute most engineering projects such as earth dams, embankments, pavements, and engineered slopes because of their high precompression stresses and shear strength. The shear strength of compacted soils is a key soil property in the design of earth structures but it is seldom determined correctly due to their unsaturated state. Research shows that there exists a close relationship between the soil-moisture state and shear strength of unsaturated soils [1-4]. It is widely accepted that the shear strength of unsaturated soils can be expressed in terms of: (i) the effective stress principle or single stress state variable, similar to saturated soils [57] or, (ii) the two stress state variable principle [8]. Equations 1 and 2 are the most commonly modified shear strength equations for unsaturated soils for single and two stress state variables, respectively.

$$
\begin{gathered}
\tau=\mathrm{c} \phi+\left[\left(s-u_{\mathrm{a}}\right)+\chi\left(u_{\mathrm{a}}-u_{\mathrm{w}}\right)\right] \tan \phi \phi \\
\tau=\mathrm{c} \phi+\left(s-u_{\mathrm{a}}\right) \tan \phi \phi+\left(u_{\mathrm{a}}-u_{\mathrm{W}}\right) \tan \phi
\end{gathered}
$$

where $\tau=$ shear strength, $\mathrm{c}^{\prime}=$ effective cohesion, $\sigma=$ normal total stress, $u_{\mathrm{a}}=$ pore-air pressure, $u_{\mathrm{w}}=$ porewater pressure, $\chi=$ value ranging between 0 to $1, \phi^{\prime}=$ effective friction angle, and $\phi^{\mathrm{b}}=$ angle indicating a change in shear strength due to matric suction. Parameters $\chi\left(u_{\mathrm{a}}-u_{\mathrm{W}}\right) \tan \phi \phi$ and $\left(u_{\mathrm{a}}-u_{\mathrm{W}}\right) \tan \phi^{\mathrm{b}}$ in Equations 1 and 2, respectively, are the shear strength as a result of matric suction $\left(\mathrm{u}_{\mathrm{a}}-\mathrm{u}_{\mathrm{w}}\right)$. Experimental results show that there is no unique relationship between $\chi$ (used in the single stress variable framework) and the degree of saturation but rather $\chi$ depends on soil type and degree of saturation. It is also reported in the literature that matric suction is due to pore water existing in the meniscus form between soil particles. In unsaturated soils, the pore-water arrangement and the associated menisci is dependent on the particle surface properties, shape, size, and pore-water chemistry. Therefore, the effect of matric suction on constitutive behaviour of soil is non-uniform and nonhomogeneous [9]. Lu and Likos [10] argued that $\phi^{\mathrm{b}}$ has uncertainties over a wide range of saturation and limits its practical application. Other researchers argue that compression indices of soils decrease with increasing suction $[11,12]$, increase with increasing suction $[13,14]$ or not affected by matric suction $[15,16]$. These observations on the compression indices complicate the interpretation of unsaturated soil behaviour and more research is needed. The application of unsaturated soil mechanics in practice faces many practical challenges: test equipment for unsaturated soils is expensive; test method is complex; longer times are required. Hence, there is a need for a simplified method of estimating the shear strength of unsaturated soil using conventional test equipment and within a practical testing duration. The rate of pore-water dissipation in unsaturated soils is much lower than the rate of load application in the field and can be approximated by the constant water content tests in the laboratory. Bishop and Donald [17], Satija [18] and Rasool, et al.[19] showed that constant water content tests reduces the time for testing unsaturated soils. In the constant water content test, the pore-air pressure is drained to reflect the field conditions.

\footnotetext{
${ }^{*}$ Corresponding author: cecleong@ntu.edu.sg
} 
Several models have been developed to estimate the shear strength of unsaturated soils and are either fittingtype models from experimental data [2, 20-23]; or prediction-type models [24-28]. The fitting-type shear strength equations have been reported to provide a better estimation than the prediction-type despite the fact that they require more experimental shear strength results [29]. Most of these models rely on some basic soil parameters and the soil-water characteristic curve (SWCC). The determination of the SWCC is not straight forward. Furthermore, there is no single universal SWCC for all soil types since the SWCC depends on the soil structure, void ratio, mineralogy, and path (drying or wetting).

In this paper, an empirical model is proposed to estimate the shear strength of compacted residual soil under different initial compaction water contents and net normal stresses. Saturated and unsaturated shear tests were conducted under constant water content tests with a conventional direct shear apparatus. This approach reduces the testing time and cost associated with constant suction tests widely used for unsaturated shear strength determination.

\section{Materials and methods}

\subsection{Residual soils}

The soil used in this study was a reconstituted residual inorganic elastic silt classified as $\mathrm{MH}$ (Unified Soil Classification System, USCS); from the Bukit Timah Granite of Singapore. The residual soil was air dried and sieved through $2.36 \mathrm{~mm}$. Only soil passing through this sieve was used in this study. The particle size distribution consisted of $41 \%$ sand and $59 \%$ fines. The soil has a liquid limit of $56 \%$, plastic limit of $36 \%$, plasticity index of $20 \%$ and specific gravity of 2.65 .

A maximum dry density of $1.61 \mathrm{Mg} / \mathrm{m}^{3}$ at an optimum moisture content of about $22.5 \%$ was observed from the Standard Proctor test determined in accordance with ASTM[30] as shown in Figure 1.

\subsection{Sample preparation}

Five water contents $(\mathrm{A}-\mathrm{E})$ shown on Figure 1 were chosen on the compaction curve to prepare the soil specimens. Point $\mathrm{C}$ is at the optimum water content, points $\mathrm{A}$ and $\mathrm{B}$ are on the dry side of the optimum whereas points D and E are on the wet side of optimum. Points B and $\mathrm{D}$ have approximately the same dry density of 1.59 $\mathrm{Mg} / \mathrm{m}^{3}$ as well as points A and E having dry density of $1.54 \mathrm{Mg} / \mathrm{m}^{3}$ but different water contents. The specimens were statically compacted using a CBR machine. At each selected water content, the mass of the soil required to give the corresponding dry density on the standard Proctor compaction curve was calculated and compressed directly into a circular direct shear box of $63.5 \mathrm{~mm}$ diameter to give a final specimen height of $20 \mathrm{~mm}$.

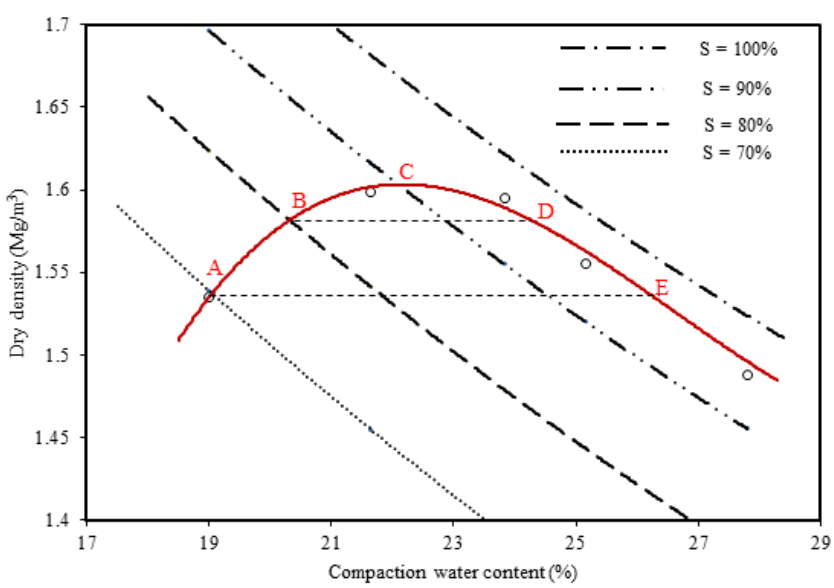

Fig. 1. Standard Proctor compaction curve

\subsection{Suction measurement}

Although matric suction can be measured during constant water content test, only initial suctions were measured in this study using the filter paper method in accordance to ASTM D5298-16 [31]. The initial matric suctions are summarised in Table 1.

Table 1. Initial matric suction

\begin{tabular}{|c|c|c|c|c|c|}
\hline $\begin{array}{l}\text { Compaction } \\
\text { Water } \\
\text { Content (\%) }\end{array}$ & 19.0 & 21.0 & 22.5 & 24.2 & 26.0 \\
\hline $\begin{array}{l}\text { Degree of } \\
\text { Saturation } \\
(\%)\end{array}$ & 68.7 & 75.8 & 81.1 & 87.1 & 93.5 \\
\hline $\begin{array}{l}\text { Initial Matric } \\
\text { Suction }(\mathrm{kPa})\end{array}$ & 432.1 & 312.3 & 148.4 & 71.9 & 18.6 \\
\hline
\end{tabular}

\subsection{Direct shear tests}

Two states of saturation for each compaction water content were used: as-compacted and saturated by water inundation. A conventional direct shear box was used for both saturated and unsaturated tests. For the saturated tests, ASTM D3080/D3080M-11 [32] was followed. The shear box containing the compacted soil specimen was inundated in the direct shear apparatus for at least 24 hours before application of the normal load. After 24 hours, the specimens were assumed to be saturated. Earlier, this was verified by determining the degree of saturation of the specimen inundated under the highest normal load. The compacted specimens were subjected to four different predetermined vertical loads of 125, 250, 500 , and $1000 \mathrm{~N}$. The shearing rate was set at 0.00694 $\mathrm{mm} / \mathrm{min}$ to ensure that the shearing was performed under fully drained condition. For the as-compacted specimens (unsaturated), consolidation was done at constant water content under the same vertical loads as for the saturated specimens. A fast shearing rate of $1 \mathrm{~mm} / \mathrm{min}$ was adopted for the unsaturated tests to reduce variations in matric suction during shearing due to evaporation. When 
shearing at a high displacement rate, the soil behaviour may not be fully drained and excess pore water pressures are expected but the use of total cohesion accounts for any possible variations in the matric suction due to excess pore-water pressures.

\section{Results and discussion}

\subsection{Saturated tests}

Generally, the soil specimens experienced dilation at lower normal loads and compression at higher normal loads during shearing. However, the peak and residual shear stresses for these soil specimens were less than 5 $\mathrm{kPa}$. In addition, the shear stresses for soil specimens compacted on the dry of optimum are higher than those compacted on the wet side of optimum at comparable dry unit weight and under the same normal load. From the plots of the peak shear and applied net normal stresses, effective stress shear strength parameters were obtained. The effective cohesion and effective friction angles for the saturated soil specimens are summarised in Table 2.

Table 2. Effective cohesion and friction angle for saturated compacted specimens

\begin{tabular}{cccc}
\hline $\begin{array}{c}\text { Compaction } \\
\text { water content of Dry Density } \\
\text { soil specimen } \\
(\%)\end{array}$ & $\begin{array}{c}\text { Effective } \\
\text { cohesion, } \\
\mathrm{c}^{\prime}\left(\mathrm{Mg} / \mathrm{m}^{3}\right)\end{array}$ & $\begin{array}{c}\text { Effective } \\
\text { friction } \\
\text { angle, } \phi^{\prime}\left({ }^{\circ}\right)\end{array}$ \\
\hline 19.0 & 1.54 & 0.0 & 35.0 \\
21.0 & 1.59 & 0.0 & 34.6 \\
22.5 & 1.61 & 0.0 & 34.1 \\
24.2 & 1.59 & 0.0 & 31.8 \\
26.0 & 1.54 & 0.0 & 31.8 \\
\hline
\end{tabular}

\subsection{As-compacted tests}

Like the saturated specimens, similar trends in volume change and shear strength were observed for the ascompacted (unsaturated) specimens. The peak shear stresses for the unsaturated specimens at different net normal stresses are plotted in Figures 2 and 3 for only compaction water content of 19.0 and $26.0 \%$, respectively. The full line represents the saturated test while the dashed lines represent the unsaturated peak shear stresses of unsaturated tests at the same gradient as the saturated line. It can be observed from

Figure 2 that a single line goes through all the peak shear stresses of the unsaturated tests indicating a negligible change in matric suction at higher net normal stresses. In Figure 3, the dashed line shifts towards the full line with the increase in net normal stress indicating an observable change in matric suction. From Equation 2, the shear strength equation for unsaturated soils can be rewritten as

$$
\tau=C+\left(\sigma-u_{\mathrm{a}}\right)_{\mathrm{f}} \tan \phi \varnothing
$$

where $\mathrm{C}$ is total cohesion expressed as

$$
C=c^{\prime}+\left(u_{\mathrm{a}}-u_{\mathrm{W}}\right)_{\mathrm{f}} \tan \phi^{\mathrm{b}}
$$

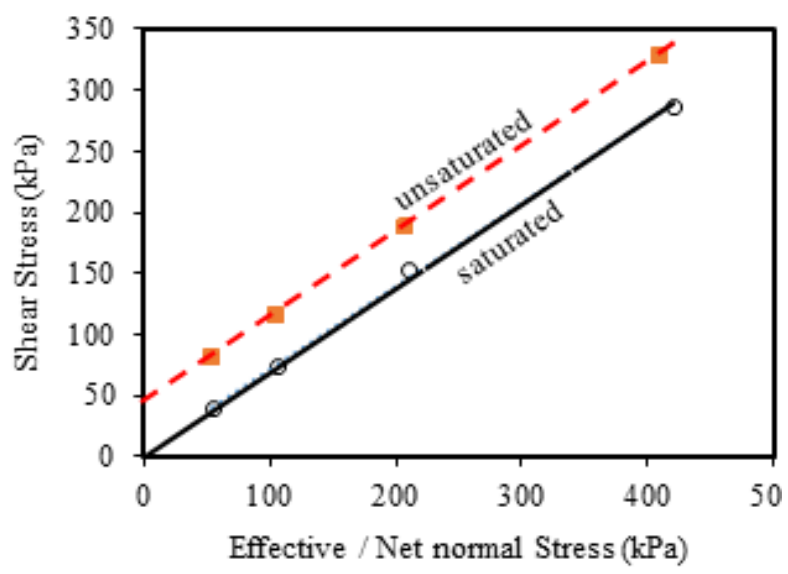

Fig. 2. Maximum shear and normal stress for soil sample at $19 \%$ compaction water content

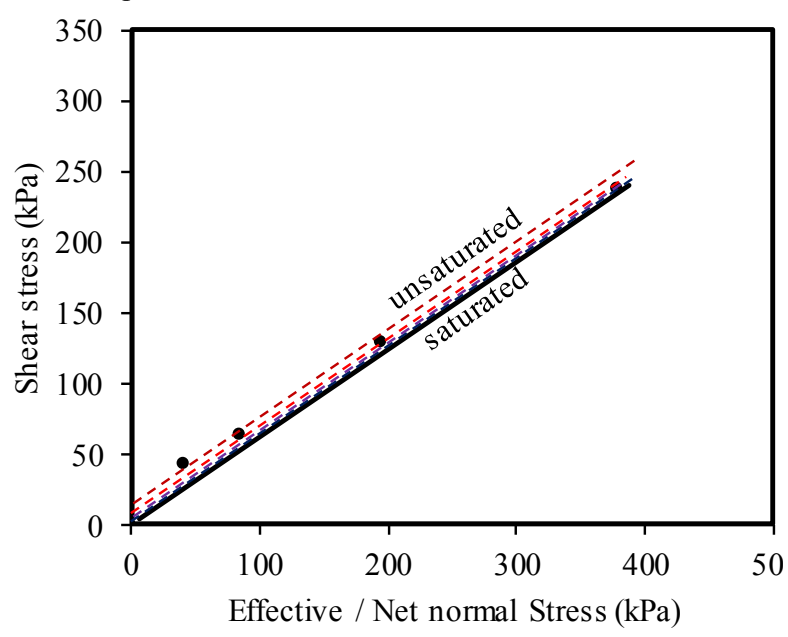

Fig. 3. Maximum shear and normal stress for soil sample at $26 \%$ compaction water content

The total cohesion is taken as the intercept on the shear stress versus effective/net normal stress plot and summarized in Table 3. From Equation 4, the value of $\phi^{b}$ can be computed. Equation 2 can be further expressed in terms of Bishop's $\chi$ value, (Equation 1), as in Equation 5.

$$
\chi=\frac{\tan \phi^{\mathrm{b}}}{\tan \phi^{\prime}}
$$

With the computed values of $\phi^{\mathrm{b}}$ and the effective friction angles, the equivalent $\chi$ values can be computed from Equation 5. For compaction water contents of 22.5, 24.2 and $26.0 \%$ only the $\phi^{\mathrm{b}}$ indicated with $*$ is used as it is assumed that under the low net normal stress, the matric suction is unchanged and remained at the initial matric suction measured. The equivalent $\chi$ values are also supplemented with data from the literature (Table 4) and plotted in Figure 4 . The $\chi$ values are bounded by two pairs of parallel upper bound and lower bound sloping lines. 
Table 3. Computed average $\phi^{\mathrm{b}}$ from compacted specimens at different compaction water contents.

\begin{tabular}{|c|c|c|c|c|}
\hline $\begin{array}{l}\text { Compaction } \\
\text { Content }(\%)\end{array}$ & water & $\begin{array}{c}\text { Suction } \\
(\mathrm{kPa})\end{array}$ & $\mathrm{C}(\mathrm{kPa})$ & $\phi^{\mathrm{b}}\left({ }^{\circ}\right)$ \\
\hline 19.0 & & 432.1 & 47.4 & 6.2 \\
\hline 21.0 & & 312.3 & 47.1 & 8.6 \\
\hline \multirow{4}{*}{22.5} & & \multirow{4}{*}{148.4} & 40.2 & $15.1 *$ \\
\hline & & & 37.3 & 14.1 \\
\hline & & & 35.4 & 13.3 \\
\hline & & & 7.3 & 2.7 \\
\hline \multirow{4}{*}{24.2} & & \multirow{4}{*}{71.9} & 28.3 & $21.3^{*}$ \\
\hline & & & 25.1 & 19.2 \\
\hline & & & 16.2 & 12.5 \\
\hline & & & 12.4 & 9.5 \\
\hline \multirow{4}{*}{26.0} & & \multirow{4}{*}{18.6} & 11.4 & $30.1 *$ \\
\hline & & & 10.3 & 27.8 \\
\hline & & & 8.1 & 22.8 \\
\hline & & & 5.2 & 14.7 \\
\hline
\end{tabular}

Table 4. Properties of soils tested in direct shear from previous studies.

\begin{tabular}{cccc}
\hline Reference & $\begin{array}{c}\text { USCS Soil } \\
\text { description }\end{array}$ & Condition & $\begin{array}{c}\text { Test } \\
\text { procedure* }\end{array}$ \\
\hline$[33]$ & SP-SC, & Compacted & $\mathrm{CW}$ \\
{$[34]$} & SP-SM, & Compacted & $\mathrm{CS}$ \\
{$[35]$} & $\mathrm{ML}$ & Undisturbed & $\mathrm{CW}$ \\
{$[36]$} & $\mathrm{ML}$ & Undisturbed & $\mathrm{CS}$ \\
\hline
\end{tabular}

* $\mathrm{CW}=$ constant water content, $\mathrm{CS}=$ constant suction

It can be observed that the range of degree of saturation for a particular $\chi$ bounded by the upper and lower bounds is small. The lower bound lines of $\chi$ can be represented by Equation 6 .

$$
\chi\left(S_{\mathrm{r}}\right)=\left\{\begin{array}{l}
4.5 S_{\mathrm{r}}-3.5 \text { for } 0.8 \leq S_{\mathrm{r}} \leq 1 \\
0.2 S_{\mathrm{r}}-0.06 \text { for } 0.3 \leq S_{\mathrm{r}}<0.8 \\
0 \quad \text { for } S_{\mathrm{r}}<0.3
\end{array}\right.
$$

where $S_{\mathrm{r}}$ is the degree of saturation.

Equation 2 can be combined with Equation 6 to give a lower bound shear strength model for unsaturated soils shown as Equation 7.

$$
\tau=\mathrm{c} \phi+\left(\mathrm{s}-u_{\mathrm{a}}\right) \tan \phi \phi+\left(u_{\mathrm{a}}-u_{\mathrm{W}}\right) \chi\left(S_{\mathrm{r}}\right) \tan \phi \phi
$$

Figure 5 shows a comparison of the estimated and measured shear strength using Equation 7 for data from [37-39]. It can be observed that the measured shear strength is higher than the estimated shear strength using the proposed model. This model can be used to obtain a conservative estimate of shear strengths for unsaturated soils.

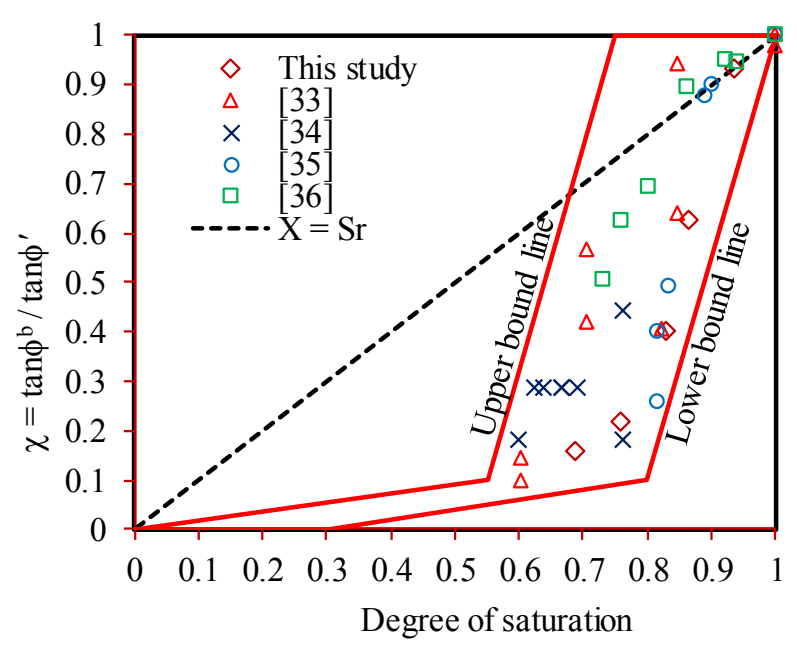

Fig. 4. Equivalent $\chi$ value versus degree of saturation.

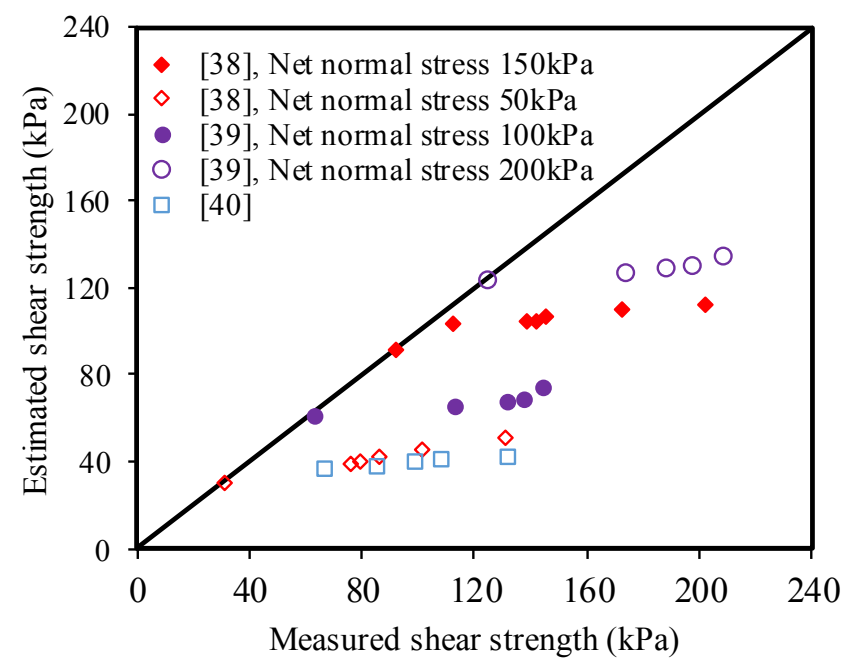

Fig. 5. Estimation of the shear strength using the proposed model.

\section{Conclusion}

The shear strength of compacted residual soils was determined using constant water content direct shear tests and interpreted using the extended Mohr-Coulomb failure criterion for unsaturated soils. A lower bound shear strength model was suggested for a conservative estimate of shear strength of unsaturated soils that should appeal to the practicing geotechnical engineers.

The first author acknowledges the SINGA scholarship for his PhD study.

\section{References}

1 J. B. Burland and J. E. B. Jennings, Géotechnique, 12, 2, 125-144, (1962).

2 D. G. Fredlund et al., Can. Geotech. Rev. Can., 321, 313-321, (1978). 
3 S. K. Vanapalli et al., Proc. 51st Can. Geotech. Conf., 87-94, (1998). Y. Matsushi and Y. Matsukura, Bull. Eng. Geol. Environ., 65, 4, 449-455, (2006).

5 D. Croney et al., (1958).

6 A. Bishop, Tek. Ukebl., 39, 859-863, (1959).

7 A. W. Bishop and G. E. Blight, Géotechnique, 13, 3, 177-197, (1963). D. G. Fredlund and N. R. Morgenstern, $J$. Geotech. Div., 103, GT5, 447-466, (1977). E. C. Leong, Indian Geotech. Conf., 103, 5, 447466, (2016). N. $\mathrm{Lu}$ and W. J. Likos, J. Geotech. Geoenvironmental Eng., 132, 2, 131-142, (2006). H. Q. Pham and D. G. Fredlund, Can. Geotech. Conf. Saskatoon, Canada, 173-181, (2005). (2013). V. Sivakumar and S. J. Wheeler, Géotechnique, 50, 4, 359-368, (2000). F. C. Silva et al., Proc. third Int. Conf. unsaturated soil, 133-137, (2002).

S. Imhoff et al., Soil Sci. Soc. Am. J., 68, 1, 17, (2004).

K. Cui et al., Geoderma, 156, 3-4, 337-345, (2010).

17 A. W. Bishop and I. B. Donald, Proc. 5th Int. Conf. Soil Mech. Found. Eng., 13-21, (1961).

B. S. Satija, Indian Institute of Technology, Dheli, (1978).

A. M. Rasool et al., 6th Asia Pacific Conf. Unsaturated Soils, 267-273, (2015).

S. K. Vanapalli et al., Can. Geotech. J., 33, 3, 2, (1996).

D. W. Rassam and C. Freeman, Geotech. Test. J., 25, 2, 215-220, (2002).

O. M. Vilar, Can. Geotech. J., 43, 10, 1088-1095, (2006).

G. Chen et al., Appl. Mech. Mater., 438-439, 1176-1180, (2013).

A.-L. Oberg and G. Sallfors, Geotech. Test. Journal, GTJODJ, 20, 1, 40-48, (1997).

N. Khalili and M. H. Khabbaz, Géotechnique, 48, 5, 681-687, (1998).

L. Miao et al., Eng. Geol., 65, 4, 261-267, (2002).

C. Kayadelen et al., Environ. Geol., 53, 4, 891901, (2007).

P. Chen et al., J. Appl. Math., 2013, (2013).

29
ASTM D698-12e2, ASTM Int. West Conshocken, $P A, 2010$, (2012).

ASTM D5298 - 16, ASTM International, West Conshocken, PA, 2003. (2010).

ASTM D3080/D3080M-11, ASTM Int. West Conshocken, PA, 2003, (2003).

A. Heitor et al., 18th Int. Conf. Soil Mech. Geotech. Eng., 1007-1011, (2013).

S. Kato et al., 5th Int. Conf. Unsaturated Soils, 265-270, (2011).

A. Jotisankasa and W. Mairaing, J. Geotech. Geoenvironmental Eng., 136, 3, 533-537, (2010). J. K. M. Gan et al., Can. Geotech. J., 25, 3, pp.500-510, (1988).

H. Rahardjo et al., Can. Geotech. J., 41, 421-436, (2004).

T. M. Thu et al., J. Geotech. Geoenvironmental Eng., 132, 3, 411-419, (2006).

S. Nam et al., Eng. Geol., 122, 3-4, 272-280, (2011). 